\title{
Hybrid AC-DC Offshore Wind Power Plant Topology: Optimal Design
}

\author{
M. de Prada, L. Igualada, C. Corchero, O. Gomis-Bellmunt Senior Member, IEEE, and \\ A. Sumper, Member, IEEE.
}

\begin{abstract}
The aim of this paper is to present an hybrid AC-DC offshore wind power plant (OWPP) topology and to optimize its design in order to minimize the OWPP's total cost. This hybrid concept is based on clustering wind turbines and connecting each group to an AC/DC power converter installed on a collector platform which is located between the $\mathrm{AC}$ wind turbine array and the HVDC offshore platform. Thereby, individual power converters of each wind turbine are not required, since such AC/DC converters can provide variable speed generator control for each cluster. The optimal design for an OWPP based on the hybrid AC-DC topology is formulated as a MINLP problem. The capital costs of each component within the OWPP as well as the costs associated to the inherent losses of this topology are minimized. The optimal number of AC/DC converters and offshore collector platforms needed, as well as their locations, are determined. The cable route connecting the wind turbines between each other is also optimized. The results suggests a good potential for the hybrid AC-DC OWPP topology achieving a total cost saving of $3.76 \%$ for the case study compared to the conventional OWPP topology.
\end{abstract}

Index Terms-Offshore Wind Power Plants (OWPPs) optimal design, Mixed Integer Non Linear Programming (MINLP), High voltage direct current (HVDC), Variable frequency wind farm, Wind power generation

\section{NOTATION}

Sets

$C \quad$ Set of submarine cables $c \in C$

$\mathcal{I} \quad$ Set of wind turbines $i, j \in \mathcal{I}$

$\mathcal{K} \quad$ Set of power converters $k \in \mathcal{K}$

$\mathcal{S} \quad$ Set of offshore platforms $s \in \mathcal{S}$

\section{Parameters}

$A_{k, s} \quad$ Adjacency matrix between AC/DC converters

$k \in \mathcal{K}$ and intermediate platforms $s \in \mathcal{S}$

$C^{E} \quad$ Cost of energy [€/MWh]

$C^{C} \quad$ Offshore cable installation cost $[\mathrm{M} € / \mathrm{km}]$

$C^{I} \quad$ Cost of the AC inter-array cables $[\mathrm{M} € / \mathrm{km}]$

$C^{X} \quad$ Cost of the DC export cables [M€/km]

$C^{K} \quad$ Cost of an AC/DC power converter [M€/MW]

$C^{S} \quad$ Cost of the offshore collector platforms [M€]

$D_{i, j}^{T T} \quad$ Distance between wind turbines $i, j \in \mathcal{I}[\mathrm{km}]$

$D_{i, k}^{T C} \quad$ Distance between wind turbines $i \in \mathcal{I}$ and AC/DC converters $k \in \mathcal{K}[\mathrm{km}]$

This work was supported by the Ministerio de Economía y Competitividad, Plan Nacional de I+D+i under Project ENE2012-33043 and by FEDER structural funds (EFRD, European Funds for Regional Development) of the European Commission that have cofinanced the technological and scientific equipment of the Institute used in the research or technological development subject of dissemination.

M. de Prada, L. Igualada, and C. Corchero are with the Catalonia Institute for Energy Research (IREC), Jardins de les Dones de Negre 1, 2a. 08930 Sant Adrià de Besòs, Barcelona (Spain) (e-mail: mdeprada@irec.cat).

O. Gomis-Bellmunt, and A. Sumper, are with IREC and the Centre d'Innovació Tecnològica en Convertidors Estàtics i Accionaments (CITCEA-UPC), Departament d'Enginyeria Elèctrica, Universitat Politècnica de Catalunya ETS d'Enginyeria Industrial de Barcelona (ETSEIB), Av. Diagonal, 647, Pl. 2. 08028 Barcelona, Spain.
$D_{s}^{P P} \quad$ Distance between collector platforms $s \in \mathcal{S}$ and the HVDC offshore platform [km]

$\bar{f} \quad$ Maximum admissible electrical frequency $[\mathrm{Hz}]$

$f \quad$ Minimal admissible electrical frequency $[\mathrm{Hz}]$

$\bar{L} \quad$ Lifetime of an offshore wind power plant [h]

$N \quad$ Number of wind turbines

$\bar{N}_{c} \quad$ Maximum number of wind turbines that can be connected to an inter-array cable $c \in C$

$\bar{P}_{i} \quad$ Maximum available power of each wind turbine $i \in \mathcal{I}[\mathrm{MW}]$

$P_{i, k} \quad$ Power generated by each wind turbine $i \in \mathcal{I}$ controlled by converter $k \in \mathcal{K}$ [MW]

$P^{N} \quad$ Nominal power of each wind turbine $i \in \mathcal{I}$ [MW]

Variables

- Continuous positive variables:

$f_{k} \quad$ Electrical frequency operated in each converter $k \in \mathcal{K}[\mathrm{Hz}]$

- Binary decision variables

$h_{s} \quad$ Offshore collector platform $s \in \mathcal{S}$

$q_{k} \quad$ Power converter $k \in \mathcal{K}$

$u_{i, j, k, c}$ Wind turbine $i \in \mathcal{I}$ connected to wind turbine $j \in \mathcal{I}$ controlled by converter $k \in \mathcal{K}$ through cable $c \in C$

$x_{i, k, c} \quad$ Wind turbine $i \in \mathcal{I}$ connected to converter $k \in \mathcal{K}$ by cable $c \in C$

$y_{i, k} \quad$ Wind turbine $i \in \mathcal{I}$ controlled by converter $k \in \mathcal{K}$

$z_{k, c} \quad$ Converter $k \in \mathcal{K}$ connected to cable $c \in C$

\section{LIST OF ACRONYMS}

$\begin{array}{ll}\text { CAPEX } & \text { Capital expenditures } \\ \text { EWEA } & \text { European wind energy association } \\ \text { HVAC } & \text { High voltage alternating current } \\ \text { HVDC } & \text { High voltage direct current } \\ \text { LCC } & \text { Line commutated converter } \\ \text { MINLP } & \text { Mixed integer non linear programming } \\ \text { NREAP } & \text { National renewable energy action plan } \\ \text { OWPP } & \text { Offshore wind power plant } \\ \text { SLPC-VF } & \text { Single large power converter } \\ \text { VSC } & \text { Voltage source converter }\end{array}$

\section{INTRODUCTION}

O FFSHORE wind is a promising energy source which has attracted world-wide attention in recent years, mainly because it provides higher energy yields than onshore and there are less space limitations, which allows the possibility of using larger wind turbines [1].

In Europe, the cumulative offshore wind capacity grew from $36 \mathrm{MW}$ in 2000 to $6562 \mathrm{MW}$ by the end of 2013 [2], representing $2.06 \%$ of its total installed wind capacity 
[3]. Although this figure is still far from reaching onshore wind sector and it is lagging behind the objectives set by EU Member States in their National Renewable Energy Action Plans (NREAPs) [4], a substantial growth of offshore wind is expected to be seen as a result of the ambitious targets intended to be carried out not only by Europe but also by China, Japan, Korea and USA [1], [5]. In particular, EWEA forecasts that by 2020, $40 \mathrm{GW}$ offshore wind capacity could be operational in European waters and that by 2030 it could reach $150 \mathrm{GW}$, meeting $14 \%$ of the EUs total electricity consumption [6].

To date, most of the Offshore Wind Power Plants (OWPPs) transmit their generated power to the main onshore grid through a High Voltage Alternating Current (HVAC) link. There is currently one OWPP (Bard Offshore 1 in Germany [7]) in operation that is connected to shore by means of a High Voltage Direct Current (HVDC) transmission, with a few more of this type under construction in German waters. Nevertheless, the fact that OWPPs are increasingly larger in size and located further away from shore due to environmental and social aspects, leads towards the utilization of HVDC technology. Various studies have demonstrated that above a certain critical distance (approximately 60-100 km depending on the power ratings of the OWPP), HVDC transmission becomes as the most appropriate option since it reduces cable losses, decreases reactive power requirements and improves power system stability [8], [9].

For offshore wind applications, Voltage Source Converters VSC-HVDC are preferred over Line Commutated Converters LCC-HVDC as they can be connected to weak grids since they do not rely on the $\mathrm{AC}$ system to support their operation and they have less filter requirements, enabling a reduction in the size of the substation. Furthermore, the fact that offshore HVDC substations accommodates a VSC allows to operate the wind farm collection grid out of synchronism with the onshore electrical network $(50$ or $60 \mathrm{~Hz})$. Thus, taking advantage of HVDC technology and its ability to electrically decouple the OWPP from the onshore power system, several researchers have been investigating the suitability of novel OWPP designs seeking the most economical solution. Some of them suggest to extend the DC nature of the high voltage transmission to the collection grid and to consider the possibility of having an entire OWPP in DC [10]-[14]. Other alternatives aim to consider the offshore collection grid in AC by operating at a non-standard frequency [15]. Likewise, some authors propose a different OWPP topology based on removing the individual power converters of each wind turbine and connecting the entire AC offshore collection grid to a Single Large Power Converter which operates at Variable Frequency (SLPC-VF) [16]-[20] (Fig. 1). Thereby, the unique VSC-HVDC converter is in charge of controlling the entire offshore wind power plant and all the wind turbines operate at the same frequency $\left(f^{*}\right)$.

In this paper, a hybrid AC-DC OWPP concept, which is based on the SLPC-VF scheme, is presented. This proposed OWPP configuration consists of wind turbine clusters connected through AC inter-array cables to AC/DC power converters located at intermediate collector platforms, which are in turn connected to a single large DC/DC converter installed on the VSC-HVDC offshore platform by means of DC export cables. As with the SLPC-VF concept, the dedicated power electronic converters equipped in each turbine are removed

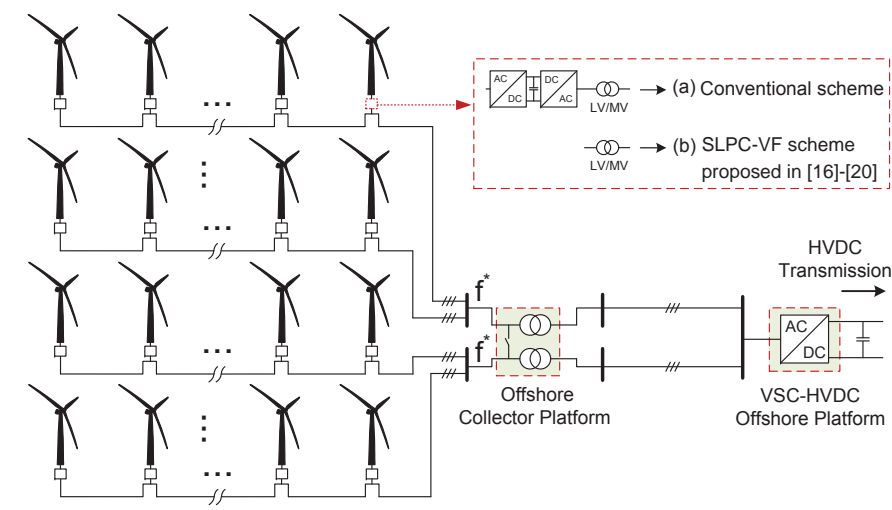

Fig. 1. Layout of an OWPP collection grid considering both the conventional topology (a) and the novel SLPC-VF concept (b) proposed in [16]-[20].

in the attempt of reducing costs. Thereby, each wind turbine cluster is controlled by one AC/DC power converter which operates at its own optimal electrical frequency [17], [21]. This concept can be applied to both synchronous and asynchronous generators. Fig. 2 shows an example of a hybrid AC-DC OWPP consisting of three wind turbine clusters operated by three $\mathrm{AC} / \mathrm{DC}$ power converters located on two offshore collector platforms.

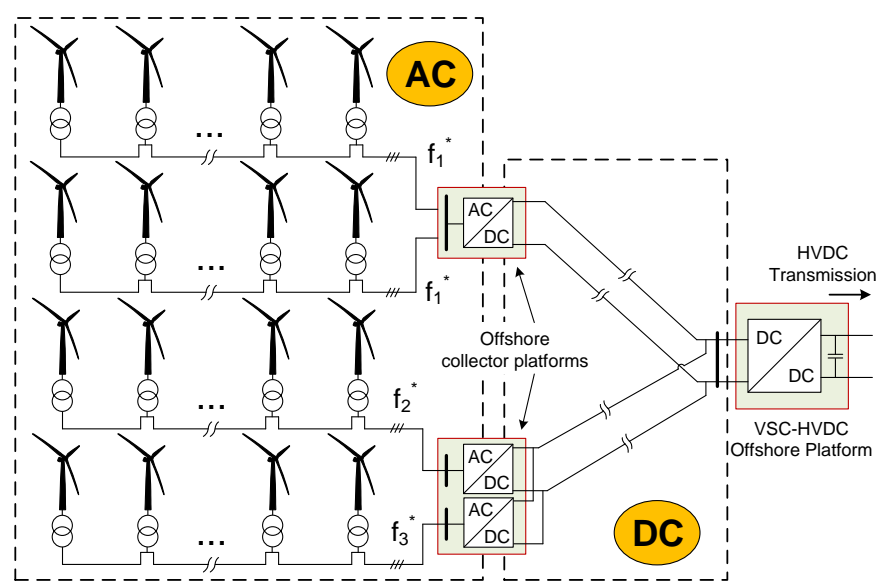

Fig. 2. Example of a hybrid AC-DC OWPP consisting of three wind turbine clusters.

On the one hand, this novel topology presents similar advantages than the SLPC-VF design in terms of capital cost savings (as fewer components are required) and maintenance cost reduction (which is especially worthwhile for offshore where accessibility to the WPP may be limited or nonexistent at certain times of the year due to harsh weather conditions) [18], [20]. On the other hand, this novel approach aims to minimize the inherent drawback of the SLPC-VF configuration, which can not ensure the optimum operational point for all wind turbines (regardless of the wind speed variability within the OWPP) because all of them are controlled simultaneously by a single power converter [17], [21]. This limitation can be significant for future OWPPs projects since larger wind farms are associated with greater wind speed differences between turbines. For example, considering an hypothetical $500 \mathrm{MW}$ OWPP with large distances between turbines (because of the wake effect), it may be more cost-effective to install several offshore collector platforms instead of a single platform and 
to group the wind turbines into a various clusters, such that each cluster consists of a power converter connected to a set of turbines with similar wind speeds.

Notice that the maximum available power can only be achieved by considering individual power converters for each turbine, so that the larger the number of power converters installed, the better the efficiency of the system, but a higher cost. Therefore, a trade-off between improving power generation efficiency of the OWPP and reducing its capital cost should be accomplished to determine the optimal design that minimizes the total OWPP cost [22], [23]. To this aim, an optimization model has been developed in order to determine the optimal number of power converters and offshore platforms needed, as well as their locations. The cable route connecting the wind turbines between each other is also optimized. The clustering design takes into account not only the capital costs of each component but also the costs associated to the inherent losses (known as $C^{P}$ losses in [18], [20]) of this topology. This hybrid AC-DC WPP topology is proposed for future OWPPs with HVDC-links where the wind speeds are supposed to be more uniform among turbines compared to onshore.

\section{Problem statement}

This paper focuses on the collection grid of an OWPP, and assumes an HVDC transmission link to the shore. The collection grid of the OWPP encompasses all the necessary equipment to collect the power generated by the wind turbines and to transmit it to the offshore platform (in this case, an offshore HVDC converter platform). It involves wind turbines, submarine inter-array cables, protections, AC/DC power converters, intermediate offshore collector platforms, submarine export cables, and the offshore HVDC platform. The latter is usually located slightly away from the OWPP to facilitate others OWPPs connections and to transmit the combined power generated by all of them through a single HVDC-link. Consequently, one or multiple intermediate collector platforms may be required to step-up the inter-array voltage and reduce the export cable losses.

Fig. 3 shows the layout of an OWPP collection grid connected to the onshore electrical network by means of an HVDC-link. As it can be seen, it consists of 24 wind turbines, 28 possible AC/DC power converters and 7 possible locations for offshore collector platforms. It is worth to remark that the dedicated power converters of each wind turbine have been removed for the case under study, so that the turbines are directly connected to the AC/DC converters placed at the offshore collector platforms. Thereby, the OWPP is divided into several clusters composed by a group of turbines connected to AC/DC power converters (one converter per cluster) operating at variable frequency.

The starting point for the optimization is that all the preliminary studies conducted during the development and consenting process (covering those aspects that are required to determine the optimal location of each wind turbine and the offshore VSC-HVDC platform [24]), such as environmental and sea bed surveys, meteorological and oceanographic analysis, etc., have already been performed.

On this basis, the model contemplates several possible locations for both collector platforms and AC/DC converters. It is considered that each offshore collector platform can

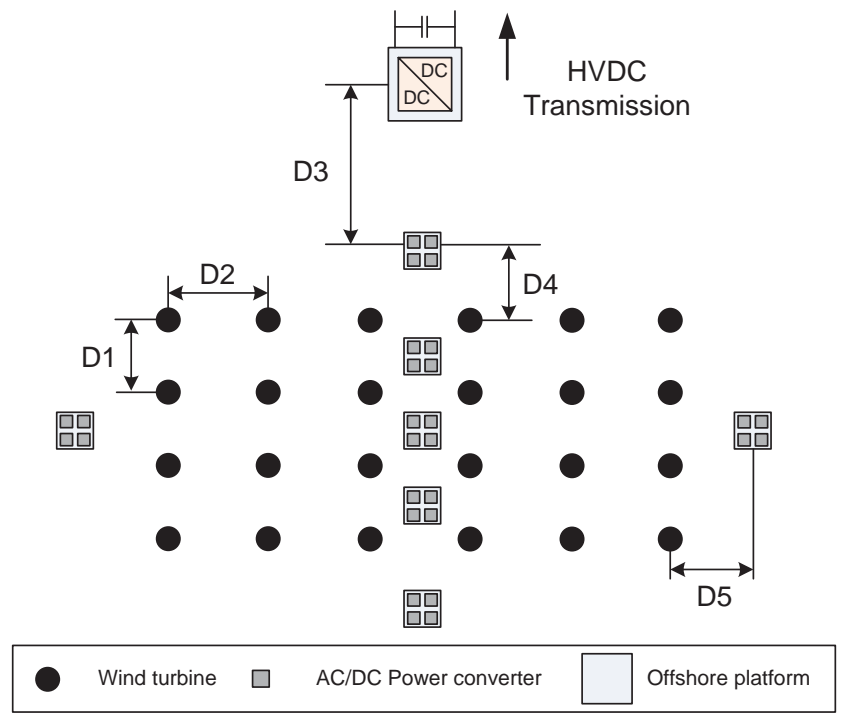

Fig. 3. Example of a schematic OWPP collection grid composed of 24 wind turbines, $28 \mathrm{AC} / \mathrm{DC}$ power converters candidates and 7 possible intermediate offshore collector platforms.

accommodate at most four AC/DC converters and a platform is only installed if a converter is assigned to it. Regarding the cable route, the model optimizes the interconnections between wind turbines, as well as the connections between turbines and converters in order to minimize the lengths of the installed cables. The problem employs one type of AC inter-array cable to connect each wind turbine either to another turbine or to a power converter, and one type of DC export cable for the connection between the AC/DC converters situated at the collector platforms and the DC/DC converter of the HVDC offshore substation.

\section{Mathematical MODEL}

In this section, the mathematical programming problem for minimizing the total cost of an offshore collection grid based on the proposed hybrid AC-DC OWPP concept described previously, is presented. This minimization process implies a trade-off between cutting down the investment costs (by decreasing the number of converters and collector platforms) and attempting to reduce the energy losses caused by the considered OWPP topology (by increasing the number of clusters, so that the wind turbines can operate closer to their optimum point).

\section{A. Technical constraints}

In the following, the technical constraints of the optimization problem are detailed.

The next set of constraints (Eqs. (1)-(4)) model the technical issues between wind turbines, power converter and offshore collector platforms.

Let $y_{i, k}$ be a set of binary variables which indicate if a wind turbine $i \in \mathcal{I}$ is controlled by a power converter $k \in \mathcal{K}$ or is not:

- $y_{i, k}=1$ if the wind turbine $i \in \mathcal{I}$ is controlled by the converter $k \in \mathcal{K}$

- $y_{i, k}=0$ otherwise 
Accordingly, Eq. 1 assures that each wind turbine $i \in \mathcal{I}$ must be controlled by one $\mathrm{AC} / \mathrm{DC}$ power converter $k \in \mathcal{K}$, so that

$$
\sum_{k \in \mathcal{K}} y_{i, k}=1 \quad \forall i \in \mathcal{I}
$$

Likewise, let $q_{k}$ be a set of binary variables which decide if the power converter $k \in \mathcal{K}$ is out of service or in operation.

- $q_{k}=1$ if the $\mathrm{AC} / \mathrm{DC}$ power converter $k \in \mathcal{K}$ is in service

- $q_{k}=0$ otherwise

Thereby, the $\mathrm{AC} / \mathrm{DC}$ power converter $k \in \mathcal{K}$ is out of service if it is not controlling any wind turbine $i \in \mathcal{I}$.

$$
q_{k} \leq \sum_{i \in \mathcal{I}} y_{i, k} \quad \forall k \in \mathcal{K}
$$

Additionally, the maximum number of wind turbines that can be connected to an AC/DC power converter $k \in \mathcal{K}$ that is in service shall not exceed the total number of turbines of the OWPP analyzed $(N)$ :

$$
\sum_{i \in I} y_{i, k} \leq N \cdot q_{k} \quad \forall k \in \mathcal{K}
$$

Finally, one converter $k \in \mathcal{K}$ will be in service only if the offshore collector platform $s$ that houses it $\left(A_{s, k}=1\right)$ is installed, then

$$
q_{k} \leq h_{s} \quad \forall s, k: A_{s, k}=1
$$

where

- $h_{s}=1$ if the offshore collector platform $s \in \mathcal{S}$ is installed

- $h_{s}=0$ otherwise

Eqs. (5)-(14) define the cable route within the OWPP. In order to properly model its specifications, the following considerations are required.

Thus, let $x_{i, k, c}$ denote a set of binary variables which define the connection between turbines and converters by means of AC cables:

- $x_{i, k, c}=1$ if the wind turbine $i \in \mathcal{I}$ is connected to the converter $k \in \mathcal{K}$ by means of the cable $c \in C$

- $x_{i, k, c}=0$ otherwise

Therefore, only if the turbine $i \in \mathcal{I}$ is controlled by the converter $k \in \mathcal{K}\left(y_{i, k}=1\right)$, this turbine can be connected to it through a single cable $c \in C$.

$$
\sum_{c \in C} x_{i, k, c} \leq y_{i, k} \quad \forall i \in \mathcal{I}, k \in \mathcal{K}
$$

To determine if a pair of wind turbines $i, j \in \mathcal{I}$ are interconnected by means of a cable $c \in C$ and controlled by a power converter $k \in \mathcal{K}$, the following set of binary variables is defined:

- $u_{i, j, k, c}=1$ if the wind turbines $i, j \in \mathcal{I}$, controlled by the converter $k \in \mathcal{K}$, are connected through the cable $c \in C$

- $u_{i, j, k, c}=0$ otherwise

Eq. 6 limits to one the number of inter-array cables $c \in C$ for every pair of wind turbines $i, j \in \mathcal{I}$ connected to one another:

$$
\sum_{c \in C} u_{i, j, k, c} \leq 1 \quad \forall i, j \in \mathcal{I}, k \in \mathcal{K}
$$

These inter-array cables have an upper limit $\left(\bar{N}_{c}\right)$ on the number of wind turbines that can be connected into it. In order to not overload the cables capacity, the sum of all pairs of turbines connected to the power converter $k \in \mathcal{K}$ through the cable $c \in C$ must be lower than this limit, as shown in Eq. (7):

$$
\sum_{i, j \in \mathcal{I}} u_{i, j, k, c} \leq \bar{N}_{c}-1 \quad \forall k \in \mathcal{K}, c \in \mathcal{C}
$$

Furthermore, only if there are two wind turbines $i, j \in \mathcal{I}$ controlled by the same power converter $k \in \mathcal{K}\left(y_{i, k}=y_{j, k}=1\right)$, these turbines can be interconnected to each other by means of one cable $c \in C$. Therefore,

$$
2 \sum_{c \in C} u_{i, j, k, c} \leq y_{i, k}+y_{j, k} \quad \forall i, j \in \mathcal{I}, k \in \mathcal{K}
$$

It is assumed as a hypothesis that each wind turbine $i \in \mathcal{I}$ can not be isolated. Similarly, each of the turbines can have at most one ingoing and one outgoing cable in order to facilitate the installation tasks carried out by the appropriate vessels. Thus, the total sum of both ingoing and outgoing cables for each turbine, must be bounded between 1 and 2 :

$$
1 \leq \sum_{\substack{k \in \mathcal{K} \\ c \in \mathcal{C}}}\left(x_{i, k, c}+\sum_{j \in \mathcal{I}: j>i} u_{i, j, k, c}+\sum_{j \in \mathcal{I}: j<i} u_{j, i, k, c}\right) \leq 2 \quad \forall i \in \mathcal{I}
$$

If two wind turbines $i, j \in \mathcal{I}$ are connected through a cable $c \in C\left(\sum_{k \in \mathcal{K}} u_{i, j, k, c}=1\right)$, any other cable $c^{\prime} \in C$ cannot be connected to them. Eq. (10) nullifies the variables associated with these cables $c^{\prime} \in C$ :

$$
\begin{aligned}
& \sum_{\substack{k \in \mathcal{K} \\
c^{\prime} \in C: c^{\prime} \neq c}}\left(x_{i, k, c^{\prime}}+x_{j, k, c^{\prime}}+\sum_{i^{\prime} \in \mathcal{I}: i^{\prime}>j} u_{j, i^{\prime}, k, c^{\prime}}+\sum_{i^{\prime} \in \mathcal{I}: i^{\prime}<j} u_{i^{\prime}, j, k, c^{\prime}}+\sum_{i^{\prime} \in I: i^{\prime}>i} u_{i, i^{\prime}, k, c^{\prime}}+\right. \\
& \left.+\sum_{i^{\prime} \in \mathcal{I}: i^{\prime}<i} u_{i^{\prime}, i, k, c^{\prime}}\right) \leq 4\left(1-\sum_{k \in \mathcal{K}} u_{i, j, k, c}\right) \quad \forall i, j \in \mathcal{I}, c \in C
\end{aligned}
$$

The number of inter-array cables connected to one converter $k \in \mathcal{K}$ is determined by both the amount of turbines controlled by it and the number of interconnections between them; it is modelled through the next set of equations:

$$
\sum_{\substack{i \in \mathcal{I} \\ c \in \mathcal{C}}} x_{i, k, c}=\sum_{i \in \mathcal{I}}\left(y_{i, k}-\sum_{\substack{j \in \mathcal{I} \\ c \in \mathcal{C}}} u_{i, j, k, c}\right) \quad \forall k \in \mathcal{K}
$$

Moreover, as ring configuration is not considered in this work, the number of wind turbine with only one outgoing cable must match the total number of cables installed within the OWPP, therefore

$$
\sum_{i \in I}\left[2-\sum_{\substack{k \in \mathcal{K} \\ c \in \mathcal{C}}}\left(\sum_{j \in I: j>i} u_{i, j, k, c}-\sum_{j \in I: j<i} u_{j, i, k, c}-x_{i, k, c}\right)\right]=\sum_{\substack{i \in \mathcal{I} \\ k \in \mathcal{K} \\ c \in \mathcal{C}}} x_{i, k, c}
$$

Let $z_{k, c}$ be a set of binary variables which determinate if a cable $c \in C$ is assigned to a specific AC/DC power converter $k \in \mathcal{K}:$

- $z_{k, c}=1$ if the cable $c \in C$ is connected to the converter $k \in \mathcal{K}$

- $z_{k, c}=0$ otherwise

Eq. (13) assures that a wind turbine $i \in \mathcal{I}$ cannot be connected to the converter $k \in \mathcal{K}$ through the inter-array cable $c \in C$ if $c$ is not assigned to $k$ :

$$
z_{k, c}=\sum_{i \in I} x_{i, k, c} \quad \forall k \in \mathcal{K}, c \in C
$$

In addition, there is no possible connection between two wind turbines $i, j \in \mathcal{I}$, controlled by a converter $k \in \mathcal{K}$ through an inter-array cable $c \in C$, if such cable is not connected to this converter $\left(z_{k, c}=0\right)$, which means

$$
u_{i, j, k, c} \leq z_{k, c} \quad \forall i, j \in \mathcal{I}, k \in \mathcal{K}, c \in C
$$


Finally, with regard to the frequency at which an AC/DC power converter $k \in \mathcal{K}$ can operate, it has an upper bound due to the maximum mechanical speed that the wind turbines can allow and because of field weakening issues. When this frequency is reached, the electrical frequency will be kept constant, and the wind turbines will locally limit their injected power adjusting the pitch angle. Likewise, the frequency of each power converter must have a lower limit as a consequence of the saturation effects of the generators and transformers. These bounds are formulated as follows

$$
\underline{f} q_{k} \leq f_{k} \leq \bar{f} q_{k} \quad \forall k \in \mathcal{K} ;
$$

\section{B. Objective function}

The objective function represents the total cost of a hybrid AC-DC OWPP considering both the capital expenditures (CAPEX) of all the components involved in the system as well as the cost associated to the energy losses within the OWPP collection grid. To ease its interpretation, the objective function is divided into four terms, as follows:

$$
F(h, u, x, y)=f_{1}(u, x)+f_{2}(h)+f_{3}(h, y)+f_{4}(y)
$$

with

$$
\begin{aligned}
f_{1}(u, x) & =\left(C^{I}+C^{C}\right)\left[\sum_{i, j}\left(D_{i, j}^{T T} \sum_{k, c} u_{i, j, k, c}\right)+\sum_{i, k, c} D_{i, k}^{T C} x_{i, k, c}\right] \\
f_{2}(h) & =\left(C^{X}+C^{C}\right) \sum_{s} D_{s}^{P P} h_{s} \\
f_{3}(h, y) & =C^{K} P^{N} \sum_{i, k} y_{i, k}+C^{S} \sum_{s} h_{s} \\
f_{4}(y) & =C^{E} L \sum_{i, k} y_{i, k}\left(\bar{P}_{i}-P_{i, k}\right)
\end{aligned}
$$

where

(17) corresponds to the capital cost of submarine AC interarray cables. $C^{I}$ refers to the cost per $\mathrm{km}$, while $C^{C}$ is the cost associated with their transport and installation. These constants have been obtained using the following cost functions reported in [25]

$$
\begin{aligned}
C^{I} & =\alpha+\beta e^{\left(\frac{\gamma I^{I}}{10^{5}}\right)} \cdot 10^{-3} \\
C^{C} & =0.365
\end{aligned}
$$

where $I^{I}$ is the AC inter-array cable ampacity (in A) for a specific conductor section and the coefficients $\alpha, \beta$ and $\gamma$ depend on the nominal voltage level.

(18) denotes the cost of the DC export cables and their installation. The DC cable costs (per $\mathrm{km}$ ) can be computed by [14]

$$
C^{X}=\psi+\sigma 2 V^{N} I^{E}
$$

where $V^{N}$ and $I^{E}$ are the cable ratings (in $\mathrm{V}$ and $\mathrm{A}$ respectively) and the constants $\psi$ and $\sigma$ depend on voltage rating of the DC cable.

(19) represents the variable component of cost related to the $\mathrm{AC} / \mathrm{DC}$ power converters in service, as well as the installed collector platforms. $C^{K}$ and $C^{S}$ refer to the cost of the power converter per MW and the cost of installing additional platforms, respectively.

(20) accounts for the cost associated with the $C^{P}$ energy losses produced by the inherent configuration of the system under study. These losses are calculated as the difference between the maximum available power of each wind turbine $i \in \mathcal{I}, \bar{P}_{i}$, and the power generated by a certain wind turbine $i \in \mathcal{I}$ controlled by a converter $k \in \mathcal{K}, P_{i, k}$. Both variables are computed as

$$
\begin{aligned}
\bar{P}_{i} & =\frac{1}{2} \rho A \bar{C}^{P} w_{i}^{3} \\
P_{i, k} & =\frac{1}{2} \rho A C_{i, k}^{P} w_{i}^{3}
\end{aligned}
$$

where $\rho$ is the air density, $A=\pi R^{2}$ is the surface covered by the rotor blades of radius $R, w_{i}$ is the average wind speed of each turbine over the lifetime of the OWPP, and $\bar{C}^{P}$ and $C_{i, k}^{P}$ are the maximum available and the actual value of the power coefficient, respectively. This power coefficient denotes the efficiency of a wind turbine defined as the ratio of actual power transferred to the rotor to the theoretical power available in the wind. It is usually expressed as a nonlinear function dependent of two parameters: tip speed ratio, $\lambda$, and pitch angle, $\beta$, [26]-[28]. The latter $(\beta)$ is set to zero in order to maximise the power generated by a wind turbine. Hence, $\mathrm{C}_{i, k}^{P}$ coefficient is only dependent on $\lambda_{i, k}$. In this paper, $\mathrm{C}_{i, k}^{P}$ is approximated by the following quadratic polynomial

$$
C_{i, k}^{P}=-0.0146 \lambda_{i, k}^{2}+0.2544 \lambda_{i, k}-0.6192
$$

for $\lambda_{i, k}$ between 4 and 10 with an accuracy of $99.96 \%$. Accordingly, $C_{i, k}^{P}$ depends on $\lambda_{i, k}$, which in turns is related to the electrical frequency of each converter, $f_{k}$, as follows

$$
\lambda_{i, k}=\frac{\omega_{k}^{T} R}{w_{i}}=\frac{2 \pi f_{k} R}{p g w_{i}}
$$

where $\omega_{k}^{T}$ is the wind turbine rotational speed, $p$ is the pair of poles of each generator, $g$ is the gearbox ratio and $f_{k}$ is the electrical frequency of the converter $k \in \mathcal{K}$. Notice that $\omega_{k}^{T}$ is only dependent on the power converter $k \in \mathcal{K}$, so that all the wind turbines connected to one common converter rotate at the same speed.

Hence, for the conventional OWPP topology in which the rotational speed of each turbine is controlled by a full power converter, this electrical frequency is optimized for each turbine as a function of its wind speed, so that the entire OWPP can operate at the optimum tip speed ratio that maximizes the power coefficient, $\bar{C}^{P}$, and therefore, its power generated. However, for the hybrid AC-DC OWPP concept, each power converter optimizes its electrical frequency, $f_{k}$, for a given set of wind speeds. Thereby, each wind turbine within a cluster operates at a different tip speed ratio (and distinct power coefficient, $C_{i, k}^{P}$ ) because the wind speeds among them, $w_{i}$, are different whereas the electrical frequency, $f_{k}$, is the same.

This non-linear objective function (Eq. (17)-(20)) together with the set of linear constraints (Eq. (1)-(15)) defines a mixed integer non-linear programming (MINLP) which is minimized to obtain the optimal design for the proposed hybrid AC-DC OWPP

\section{Tests AND RESUlts}

\section{A. Mathematical model results}

The model has been implemented in GAMS [29] and solved with DICOPT. Table I contains the dimensions of the problem. 
TABLE I

Model statistics obTained WITH GAMS

\begin{tabular}{|c|c|c|c|}
\hline No. variables & No. binary variables & No. constraints & Execution Time \\
\hline 52.563 & 52.535 & 83.641 & $13 \mathrm{~h} 5 \mathrm{~min}$ \\
\hline
\end{tabular}

The mathematical model has been applied to the hybrid ACDC OWPP displayed in Fig. 3, consisting of 24 wind turbines (6 columns and 4 rows), 28 AC/DC power converters candidates and 7 possible intermediate offshore collector platforms. The rated power of each wind turbine is $5 \mathrm{MW}\left(P^{N}\right)$ and its rotor diameter $(D) 126 \mathrm{~m}$. The optimal design obtained that minimizes the total OWPP's cost for the hybrid topology, is shown in Fig. 4.

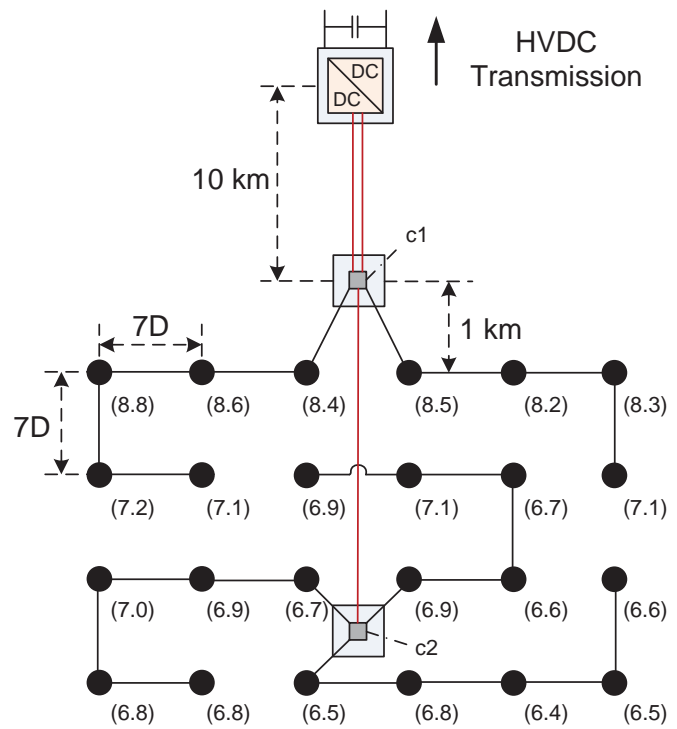

\begin{tabular}{|ll|}
\hline Wind turbine $\square \quad$ AC/DC Power converter & $\square$ Offshore platform \\
& AC inter-array cables $\square$ DC export cables \\
\hline
\end{tabular}

Fig. 4. Optimal design obtained for the hybrid AC-DC OWPP topology consisting of 24 wind turbines, 2 AC/DC power converters and 2 offshore collector platforms. The number in parenthesis indicate the average wind speed $(\mathrm{m} / \mathrm{s})$ of each turbine.

As it can be seen, the resulting layout is a feasible solution, since it satisfies all the model constraints previously mentioned. It consists of $2 \mathrm{AC} / \mathrm{DC}$ power converters installed on their respective offshore collector platforms. The distances D1 to D5, as well as the interconnections between wind turbines, are specified in Fig. 4. The numbers in parenthesis indicate the average wind speed of each turbine (in $\mathrm{m} / \mathrm{s}$ ). The operational points of each wind turbine related to their $C_{i, k}^{P}-\lambda_{i, k}$ curve are depicted in Fig. 5. As it is shown, all $\lambda_{i, k}$ values are within the admissible limits and, therefore, the polynomial approximation of the $C^{P}$ curve used in the model is valid.

The inter-array cable that has been used is a $33 \mathrm{kV}$ AC submarine cable with a cross section of $240 \mathrm{~mm}^{2}$ and an ampacity $\left(I^{I}\right)$ of 582 A. Regarding the DC export cables, a XLPE cable with a cross section of $630 \mathrm{~mm}^{2}$, an ampacity $\left(I^{E}\right)$ of $835 \mathrm{~A}$ and a voltage rating $\left(V^{N}\right)$ of $\pm 80 \mathrm{kV}$ has been selected. The total cost of the power converters and collector platforms is obtained as a result of adding a fixed cost to equation 19 of the objective function. This constant term only

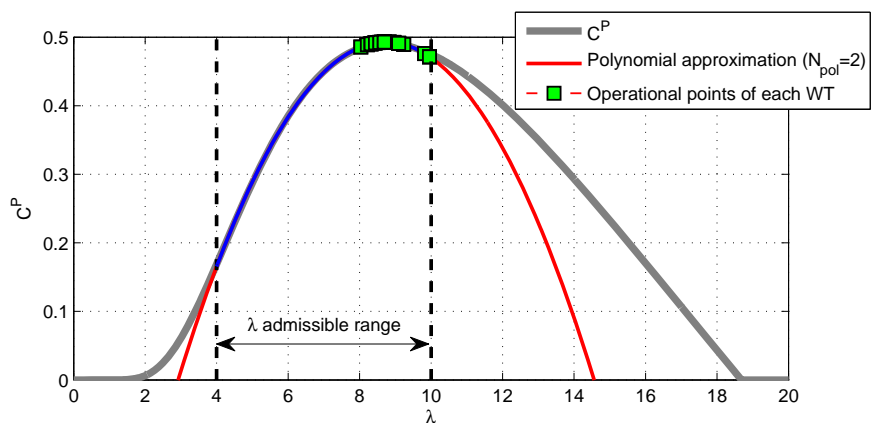

Fig. 5. $\quad C_{i, k}^{P}-\lambda_{i, k}$ curve and the polynomial approximation with all the operating points of each wind turbine $i \in \mathcal{I}$ which is controlled by the power converter $k \in \mathcal{K}$.

depends on the rated power of the OWPP analyzed $\left(P^{N} N\right)$ and it is independent on the decision variables. All parameters needed to compute $C^{I}$ and $C^{X}$, as well as the constants $C^{K}$, $C^{S}$ and $C^{E}$ used in the objective function are detailed in the Appendix.

Table II shows the breakdown of the cost for the resulting optimal hybrid AC-DC OWPP design.

TABLE II

BREAKDOWN OF THE COSTS FOR THE OPTIMAL HYBRID AC-DC OWPP DESIGN.

\begin{tabular}{|l|r|}
\hline \multicolumn{1}{|c|}{ Items } & Cost $(\mathbf{M} €)$ \\
\hline Cost of AC inter-array cables & 7.8 \\
\hline Cost of DC export cables & 6.5 \\
\hline Cost of AC/DC power converters & 14.3 \\
\hline Cost of collector platforms & 17.0 \\
\hline Cost of energy losses & 3.3 \\
\hline Total cost & $\mathbf{4 8 . 9}$ \\
\hline
\end{tabular}

The optimum frequencies for power converters $\mathrm{c} 1$ and $\mathrm{c} 2$ that minimize the $C^{P}$ energy losses for the given wind speed sets and the chosen hybrid topology are 37.498 and $31.356 \mathrm{~Hz}$, respectively. Comparing to an OWPP in which a single power converter is in charge of controlling the whole wind farm (and therefore, there is no individual converters in each turbine), the optimal hybrid AC-DC design is able to reduce the $C^{P}$ energy losses over the lifetime of such OWPP by $109 \mathrm{GWh}$, which means a cost saving of up to $5.11 \mathrm{M} €$ (considering a lifetime, $L$, of the OWPP project of 25 years).

\section{B. Application of the hybrid AC-DC OWPP topology}

The model described is a non-linear mixed-integer problem with a great amount of binary variables, as it is shown in Table I. For this reason, the dimension of the OWPP has been reduced in the mathematical model tests due to the computational limitations.

As previously mentioned in Section I, the SLPC-VF topology proposed in the literature becomes less cost-effective as the OWPP is growing in size and rated power, since the $C^{P}$ energy losses that occur due to their inherent configuration, can be significant. Thus, the hybrid AC-DC OWPP concept proposed in this paper will be profitable for such large OWPPs because the cost savings of reducing both the energy losses within the wind farm throughout its lifetime and the total length of the inter-array cables will more than likely be greater than the incremental cost of installing additional power converters and offshore collector platforms.

To demonstrate that the proposed design of a hybrid OWPP can be more economical than an OWPP based on both the conventional scheme and the SLPC-VF topology, a comparative 
cost analysis is carried out. A feasible solution that satisfies all the constraints of the model has been chosen as an example of case study for the hybrid AC-DC OWPP topology. Thereby, if such feasible solution is found to be more economical than the other topologies, its optimal design will be as well.

Fig. 6 shows the three topologies analyzed (conventional, SLPC-VF and hybrid) for an OWPP consisting of 80 wind turbines with a rated power of $5 \mathrm{MW}$ and a rotor diameter (D) of $126 \mathrm{~m}$. It is assumed that the OWPP is far enough from the shore so that the DC interconnection is technoeconomically feasible. It is laid out in a regular matrix of 10 columns and 8 rows. The spacing between two nearby wind turbines is $9 \mathrm{D}$ in the prevailing wind direction and $7 \mathrm{D}$ in its perpendicular direction, whilst the distance between the HVDC offshore platform and the nearest collector platform to it is $10 \mathrm{~km}$. All cost data used are the same as those employed in the previous example and are shown in the Appendix.

Concerning the hybrid topology (case (c)), it consists of two collector platforms and three AC/DC power converters installed on it (c1, c2 and $\mathrm{c} 3$ ). Therefore, the wind turbines are arranged into three clusters which operate at different frequencies set by their respective converters. It is worth noting that both the SLPC-VF and the hybrid topologies (cases (b) and (c)) do not have individual power converters in each wind turbine. The obtained results are presented in Table III.

$$
\text { TABLE III }
$$

Breakdown of the costs for the three OWPP topologies analyzed. All the

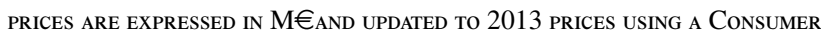
PRICE INDEX OF $2 \%$.

\begin{tabular}{|l|c|r|r|}
\hline \multicolumn{1}{|c|}{ Items } & $\begin{array}{c}\text { Conventional } \\
\text { (Fig. 5a) }\end{array}$ & $\begin{array}{c}\text { SLPC-VF } \\
\text { (Fig. 5b) }\end{array}$ & $\begin{array}{c}\text { Hybrid AC-DC } \\
\text { (Fig. 5c) }\end{array}$ \\
\hline Cost of inter-array cables & 70.1 & 70.1 & 53.7 \\
\hline Cost of export cables & 16.2 & 16.2 & 15.9 \\
\hline Cost of power converters & 41.6 & 20.7 & 46.5 \\
\hline Cost of collector platforms & 86.4 & 86.4 & 91.8 \\
\hline Cost of energy losses & 16.6 & 31.5 & 14.3 \\
\hline Total cost & $\mathbf{2 3 0 . 9}$ & $\mathbf{2 2 4 . 9}$ & $\mathbf{2 2 2 . 2}$ \\
\hline
\end{tabular}

As it is observed, the hybrid AC-DC OWPP topology (c) is the most economical option, obtaining a cost benefit of 2.7 $\mathrm{M} €$ and 8.7 M€ over the SLPC-VF (b) and conventional schemes (a), respectively. Hence, a total cost saving of up to $3.76 \%$ compared to the conventional OWPP topology can be achieved.

In general terms, the cost savings of reducing both the total inter-array cable length as well as the energy losses, coupled with the fact of not requiring dedicated power converters in each wind turbine, compensate the extra costs of installing additional offshore collector platforms and AC/DC power converters. With regard to the cost of the export cables, it remains practically unaltered for the three concepts, because even though the export cable length for the hybrid OWPP case (c) increases by $6.1 \mathrm{~km}$ compared to the other two OWPP topologies, its capital and installation cost is slightly lower.

The cost of the power converters placed in each wind turbine has been considered to be $5 \%$ of the total turbine capital cost, according to [30].

In order to perform a more accurate comparison, the cost of energy losses has taken into account both the energy lost over the lifetime of an OWPP as a result of the efficiency losses of its components (transformers, converters, cables, etc.) and due to the inherent limitations of the OWPPs topologies analyzed (transmission losses and $C^{P}$ losses, respectively).
The optimum frequency at which the single large power converter of case (b) should operate to maximize the OWPP power generation for the given set of wind speeds is $39.34 \mathrm{~Hz}$. Likewise, the optimum frequencies for power converters c1, c2 and $\mathrm{c} 3$ of the hybrid topology are $44.85,41.37$ and $37.69 \mathrm{~Hz}$, respectively. It should be remarked that all these frequencies as well as the power generated by each wind turbine have been computed for a specific set of wind speeds that represents the average wind speed of each turbine over its lifetime.

\section{Conclusion}

This paper presents a novel hybrid AC-DC offshore wind power plant (OWPP) topology and an optimization of its design in order to minimize its total cost. This proposed concept is planned for large OWPPs with an HVDC transmission link and where the single offshore HVDC platform is located slightly away from the wind turbine array to facilitate others OWPPs connections. It is based on installing one or multiple $\mathrm{AC} / \mathrm{DC}$ power converters and intermediate offshore collector platforms between the HVDC platform and the OWPP, so that the inter-array $\mathrm{AC}$ voltage is step-up and the power is transmitted by the DC export cables. Likewise, the individual power converters of each turbine are removed and each of the aforementioned AC/DC converters controls a wind turbine cluster operating at variable frequency which is optimized for a given set of wind speeds.

The optimal design for an OWPP based on the hybrid AC-DC topology is formulated as a MINLP problem. The optimization model has been developed in order to determine the optimal number of AC/DC power converters and offshore collector platforms needed, as well as their locations. Furthermore, the cable route connecting the wind turbines between each other is optimized. The results obtained demonstrate the good performance of the optimization model and suggest the hybrid AC-DC topology as an appealing OWPP alternative, since a total cost saving of up to $3.76 \%$ compared to a conventional OWPP topology can be achieved.

\section{REFERENCES}

[1] R. Berger, Offshore wind toward 2020. on the pathway to cost competitiveness, Tech. rep., Roland Berger Strategy consultants GmbH (April 2013).

[2] The European offshore wind industry - key trends and statistics 2013 , Tech. rep., European Wind Energy Association (EWEA) (January 2014).

[3] Global wind statistics 2013, Tech. rep., Global Wind Energy Council (GWEC) (February 2014).

[4] 2012 Annual Report, Tech. rep., The World Wind Energy Association (WWEA) (2013).

[5] B. Snyder, M. Kaiser, A comparison of offshore wind power development in europe and the us: Patterns and drivers of development, Applied Energy 86 (10) (2009) 1845-1856.

[6] Deep water. the next step for offshore wind energy, Tech. rep., European Wind Energy Association (EWEA) (July 2013).

[7] Bard group website 2012. [online]. available: http://www.bardoffshore.de/.

[8] N. B. Negra, J. Todorovic, T. Ackermann, Loss evaluation of HVAC and HVDC transmission solutions for large offshore wind farms, Electric Power Systems Research 76 (11) (2006) 916-927.

[9] N. Kirby, M. Luckett, L. Xu, W. Siepmann, HVDC transmission for large off shore wind farms., no. 485, IEEE ACDC Power Transmission, London, 2001

[10] N. Holtsmark, H. Bahirat, M. Molinas, B. Mork, H. K. Hoidalen, An All-DC Offshore Wind Farm With Series-Connected Turbines: An Alternative to the Classical Parallel AC Model?, IEEE Transactions on industrial Electronics 60 (2013) 2420-2428. 


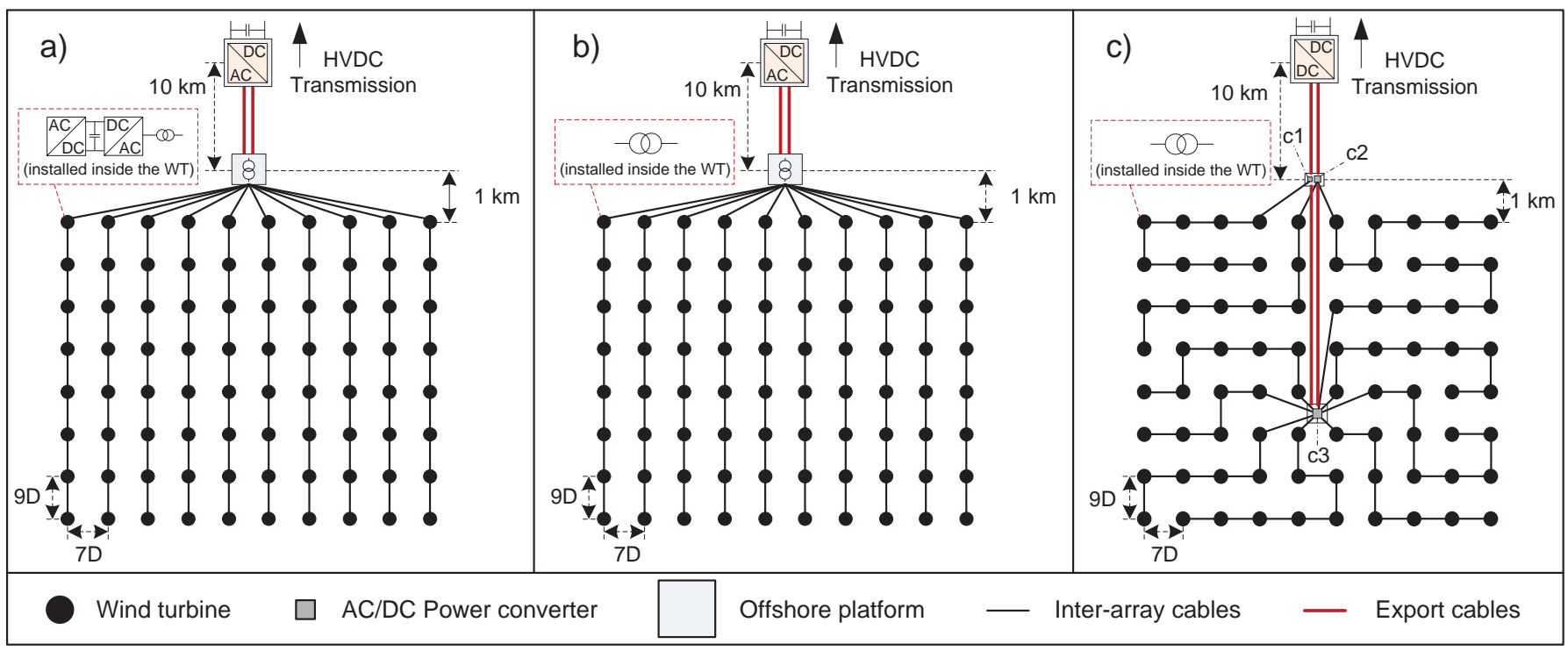

Fig. 6. Three topologies analyzed for an OWPP consisting of 80 wind turbines of 5 MW each: (a) Conventional scheme, (b) SLPC-VF scheme and (c) Hybrid AC-DC OWPP concept.

[11] D. Valcan, P. Kjaer, L. Helle, S. Sahukari, M. Haj-Maharsi, S. Singh, Cost of energy assessment methodology for offshore AC and DC wind power plants, in: 13th International Conference on Optimization of Electrical and Electronic Equipment (OPTIM), 2012, pp. 919-928.

[12] M. A. Parker, O. Anaya-Lara, Cost and losses associated with offshore wind farm collection networks which centralise the turbine power electronic converters, IET Renewable Power Generation 7 (4) (2013) 390-400.

[13] M. De Prada-Gil, J. Domínguez-García, F. Díaz-González, M. AragüésPeñalba, O. Gomis-Bellmunt, D. Berenguel-Centeno, M. Martins, G. Fullana, Analysis of DC collector grid for offshore wind power plants, in: 12th Workshop on Large-Scale Integration of Wind Power into Power Systems, 2013.

[14] G. Stamatiou, Techno-Economical Analysis of DC Collection Grid for Offshore Wind Parks, Master's thesis, University of Nottingham (2010).

[15] J. L. Domínguez-García, D. Rogers, C. Ugalde-Loo, J. Liang, O. GomisBellmunt, Effect of non-standard operating frequencies on the economic cost of offshore AC networks, Renewable Energy 44 (2012) 267-280.

[16] L. Trilla, O. Gomis-Bellmunt, A. Sudrià-Andreu, J. Liang, Control of SCIG wind farm using a single VSC, Power Electronics and Applications (EPE 2011), Proceedings of the 2011-14th European Conference, 2011, pp. 1-9.

[17] O. Gomis-Bellmunt, A. Junyent-Ferré, A. Sumper, J. Bergas-Jané, Control of a wind farm based on synchronous generators with a central HVDC-VSC converter, IEEE Transactions on power systems 26 (3) (2011) 1632-1640.

[18] D. Jovcic, N. Strachan, Offshore wind farm with centralised power conversion and DC interconnection, IET Generation, Transmission \& Distribution 3 (6) (2009) 586-595.

[19] V. Gevorgian, M. Singh, E. Muljadi, Variable frequency operations of an offshore wind power plant with HVDC-VSC, IEEE Power and Energy Society General Meeting (PES), San Diego, California.

[20] M. De-Prada-Gil, O. Gomis-Bellmunt, A. Sumper, Technical and economic assessment of offshore wind power plants based on variable frequency operation of clusters with a single power converter, Applied Energy 125 (2014) 218-229.

[21] M. de Prada Gil, O. Gomis-Bellmunt, A. Sumper, J. Bergas-Jané, Power generation efficiency analysis of offshore wind farms connected to a SLPC (single large power converter) operated with variable frequencies considering wake effects, Energy 37 (1) (2012) 455-468.

[22] S. Lumbreras, A. Ramos, Optimal Design of the Electrical Layout of an Offshore Wind Farm Applying Decomposition Strategies, IEEE Transactions on Power Systems 28 (2) (2013) 1434-1441

[23] M. Lindahl, N. F. Bagger, T. Stidsen, S. F. Ahrenfeldt, I. Arana, OptiAr- ray from DONG Energy, 12th Workshop on Large-Scale Integration of Wind Power into Power Systems, London, 2013.

[24] J. Serrano-González, M. Burgos-Payán, J. Riquelme-Santos, A New and Efficient Method for Optimal Design of Large Offshore Wind Power Plants, IEEE Transactions on Power Systems 28 (3) (2013) 3075-3084.

[25] M. Dicorato, G. Forte, M. Pisani, M. Trovato, Guidelines for assessment of investment cost for offshore wind generation, Renewable Energy 36 (8) (2011) 20432051.

[26] S. Heier, Grid Integration of Wind Energy Conversion Systems, John Wiley and Sons, 1998.

[27] Z. Lubosny, Wind Turbine Operation in Electric Power Systems, Springer, 2003.

[28] T. Ackermann, Wind Power in Power Systems, Wiley, 2005.

[29] A. Brooke, D. Kendrick, A. Meeraus, Release 2.25 gams users guide., The Scientific Press. South Francisco, USA (1992).

[30] The economics of wind energy, Tech. rep., European Wind Energy Association (EWEA) (March 2009).

[31] A guide to an offshore wind farm, Tech. rep., The Crown Estate (January 2010).

[32] Comisión Nacional de la Energía (CNE), Resultados del Mercado de Producción de Energía Eléctrica 2013, http://www.cne.es. (Accessed on $14 / 01 / 2014)$

\section{APPENDIX}

Table IV presents the parameters used for the test case, which are needed to solve the objective function detailed in Eq. 16.

TABLE IV

Parameters USED For the test Case.

\begin{tabular}{crrr}
\hline Parameters & Values & Units & Refs. \\
\hline$\alpha$ & 0.05208 & $\mathrm{M} € / \mathrm{km}$ & {$[25]$} \\
$\beta$ & 0.07551 & $\mathrm{M} € / \mathrm{km}$ & {$[25]$} \\
$\gamma$ & 234.34 & $1 / \mathrm{A}$ & {$[25]$} \\
$\psi$ & -0.012 & $\mathrm{M} € / \mathrm{km}$ & {$[14]$} \\
$\sigma$ & $1.97 \cdot 10^{-9}$ & $\mathrm{M} € /(\mathrm{km} \cdot \mathrm{VA})$ & {$[14]$} \\
$\mathrm{C}^{K}$ & 0.072 & $\mathrm{M} € / \mathrm{MW}$ & {$[31]$} \\
$\mathrm{C}^{S}$ & 2.534 & $\mathrm{M} €$ & {$[25]$} \\
$\mathrm{C}^{E}$ & 46.84 & $€ / \mathrm{MWh}$ & {$[32]$} \\
\hline
\end{tabular}

